\title{
Teaching Computer Algorithm as a Medium of Improving Problem Solving Skills in Elementary School Students
}

\author{
Zekeriya Kazanci
}

\begin{abstract}
Teaching computer algorithm is one of the basic steps of teaching computer programming. It helps the programmers to understand what the problem is and how it is supposed to be solved. Therefore this process requires a certain level of problem solving ${ }^{i}$ skills. The purpose of this experimental study is to investigate if the process of learning and using computer algorithm can improve the problem solving skills of elementary school students. The findings of this study are considered important and useful since placing a programming course into the curriculum was considered by the Ministry of Education in Turkey. The results of the study suggest that there is a significant difference between the experimental group and the control group according to their problem solving skills in favor of the experimental group.
\end{abstract}

Index Terms - Computer algorithm, computer programming, problem solving skills, elementary school students.

\section{INTRODUCTION}

Computer programming or in other words coding is undoubtedly one of the most promising professional fields of today and seemingly near future. Almost all electric or electronic devices that are widely in use today require programming. This phenomenon has been pushing many people -especially children who will constitute the future of the society to focus on programming more than ever. Just a couple decades ago, programming was considered as a very complicated procedure that can only be handled by highly trained and skilled professionals, however today it can be successfully done by amateur entrepreneurs who may not finished their high school education yet and they may gain considerable amounts of income which makes programming even more tempting for younger generations. This accomplishment potential provides educators and students the motivation for a better comprehension of programming and its applications. Programming in general is defined as "...human activity to mean the act of extending or changing a system's functionality..." by Van-Roy \& Haridi [1]. However when it comes to the computer programming Rist [2] defines it as rules of operation that are governed by the syntax and the control structures of the language used. On the other hand, Papert [3] defines computer programming with the analogy of a natural human language in that it has certain metaphors, images, and ways of thinking. As a matter of fact this language analogy is not too far from its literal meaning since computer programming basically consist of

Manuscript received May 14, 2016; revised July 19, 2016. This work was supported by Research Fund of the Cukurova University. Project Number: SBA-2016-7006.

Zekeriya Kazanci is with the Çukurova University, Turkey (e-mail: zkazanci@cu.edu.tr). programming languages which have been evolving in many ways to carry out various functions. Algorithm constitutes one of the very first and basic steps of the programming process. The word algorithm comes from the name al-Khwarizmi who was a Persian mathematician, astronomer, geographer, and scholar. Since he was a mathematician, the term was mostly used in mathematics context. However, with the development of computer technology, the term was started to be used in information technology as well. Now it constitutes the basis for almost all programing languages because it provides detailed description of the problem(s) and its (their) possible solution(s). Cormen [4] defines computer algorithm as "....any well-defined computational procedure that takes some value as input and produces some value as output.." and he also views algorithm as a tool for solving a well-specified computational problem. In addition to this Neopolitan and Naimipour [5] defines computer algorithm as “...a step by step procedure for solving a problem by applying a technique". These two definitions strongly indicate the relation between computer algorithm and problem solving. Related to problem solving with computer, Dave [6] determined 8 steps;

1) Statement of the problem or problem definition

2) Development of a model

3) Design of the algorithm

4) Checking the correctness of the algorithm

5) Implementation in some programming language

6) Analysis and study of the complexity of the algorithm

7) Program testing - debugging and profiling

8) Preparation of document

These steps can be considered in and applied the solutions of most of the real world problems one can face every day. As a matter of fact, this idea constitutes the backbone of this study; if students of elementary school begin learning computer programming and algorithm at earlier ages, can that help them to develop better problem solving skills because now they have a more systematic way to look at the problems? Allan and Kolesar [7] support this idea by their statement that in the computer science courses students gain mathematical and problem-solving skills as well while becoming familiar with the computer as a tool.

Mayer [8] approach to this situation through two questions; "What kinds of instruction enable students to learn programming productively?" and "What are the cognitive consequences of learning programming languages?" His second seems relatively more important because these cognitive consequences will create the mindset of the current and future generations. Problem solving skill can be regarded as one of the useful and rewarding cognitive consequence of learning computer programming and algorithm. Problem solving is a basic skill that human beings need several times 
in a regular day. Resnick and Glaser [9] emphasize tangible and abstract aspects of problem solving skills by defining it as "...tasks that require the invention or construction of a new strategy or material object." Butterworth and Hopkins [10] claimed that the capacity of problem solving is innate. On the other hand, Sharma, Petosa, and Heaney [11] considers "...developing problem-solving skills in school children as a basic health competency which also enable them to make informed decisions". But there are several ways to improve this innate skill of problem solving. Resnick and Glaser [9] stated that "... in the absence of complete instruction, a person must "invent" a new solution to a problem by assembling previously learned skills." This statement also indicates that previous knowledge and experiences can be transferred to newly encountered situations. Therefore this study aims to find out that if learning programming algorithm is one of those knowledge or experiences that help young learners to expand their potential in problem solving skills.

One of the main motivations of this study is that, the Turkish Ministry of Education has been considering placing a computer programming course into the high school curriculum and it was opened to the discussion and consultation of the shareholders of education. Since this consideration needs broad views from various parties from the point of its implications and consequences, this study was hoped to contribute to provide a scientific basis from the aspect of its effects on problem solving skills of elementary school students.

\section{Methodology}

The aim of this experimental study is to investigate if learning algorithm has an impact on problem solving skills of elementary school students. Randomly selected 36 sixth grade students who were divided as 18 experimental group students and 18 control group students were participated in the study from Mehmet Akif Elementary School in the province of Seyhan in the city of Adana in Turkey. The research was designed as control group/experimental group research design which can be shown with symbols as follows:

$$
\begin{array}{lllll}
\mathrm{G}_{1} & \mathrm{R} & \mathrm{O}_{1.1} & \mathrm{X} & \mathrm{O}_{1.2} \\
\mathrm{G}_{2} & \mathrm{R} & \mathrm{O}_{2.1} & & \mathrm{O}_{2.2}
\end{array}
$$

In this symbolic demonstration, $\mathrm{G}_{1}$ is experimental group, $\mathrm{G}_{2}$ is control group, $\mathrm{R}$ is their randomly assignment, $\mathrm{X}$ is the treatment for the experimental group and $\mathrm{O}$ symbolizes the pre-test and post-test.

The Information Technology course in the school program was reserved for this study for 8 weeks. "Four free on-line computer games that require problem solving skills were selected by the researcher to be used as a measurement tool. Apparently there are various measurement tools and rubrics to scale the problem solving skills of the students but in this study, computer games were chosen to attract the sincere attention of the students. The features of the games are as follows:
1) Shape Fold: This game has unfolded and unpredictable pieces of shapes which can be folded in a certain way to constitute a meaningful figure of a human, an animal or an object Fig. 1). Each figure within the game is a level and it is required to complete one figure to pass to the next level. The students' score was measured by the number of the levels accomplished in 3 minutes.

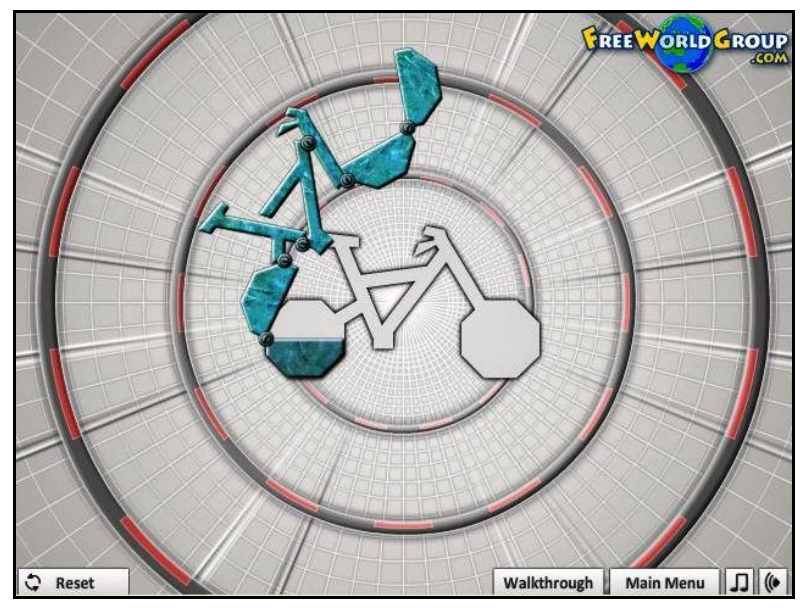

Fig. 1. Screen shot of shape fold game

2) Sliding Puzzle: This is an on-line version of classic sliding puzzle toy (Fig. 2). Players are required to slide small squares to form a figure or rank the numbers from 1 to 8 . The students' score was measured by the time they have finished the puzzle. If they cannot finish it in 5 minutes, their score is 0 .

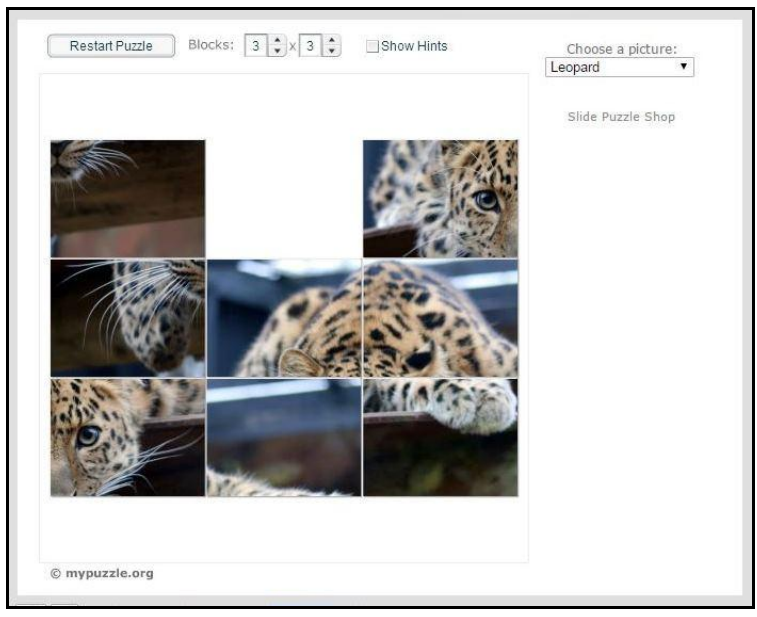

Fig. 2. Screen shot of sliding puzzle game.

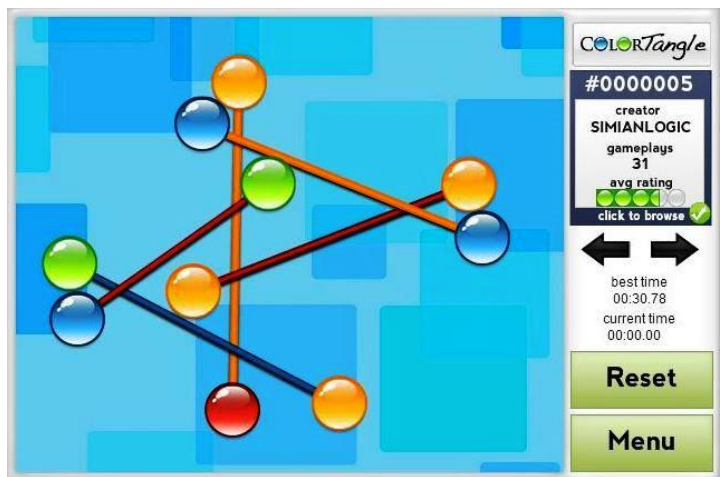

Fig. 3. Screen shot of color tangle game.

3) Color Tangle: In this game, there are colorful sticks with 
colorful balls at each ends (Fig. 3). It is required to untangle the sticks according to their colors of sticks and balls. The students' score was measured by the number of the levels accomplished in 3 minutes.

4) Unblock Me: There are various sizes and colors of rectangles in this game (Fig. 4). The aim of the game is to slide red rectangle out of the scene by sliding the other rectangles in different directions. A level can be passed at each time the red rectangle was slid out. Again the students' score was measured by the number of the levels accomplished in 3 minutes.

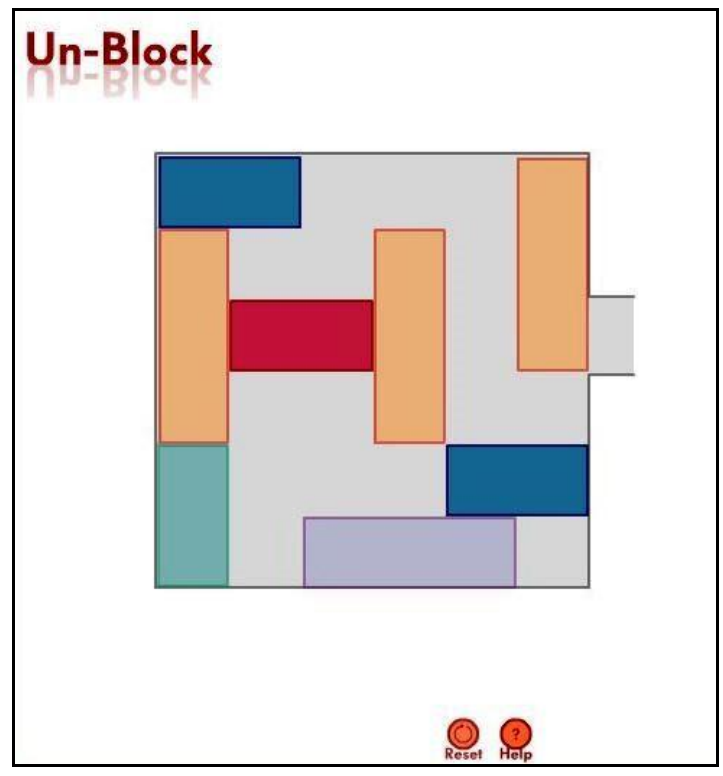

Fig. 4. Screen shot of Unblock me game.

Firstly, all students were subjected to these four games as a pre-test in order to determine their problem solving skill level at the beginning of the study. Then, a computer teacher who is also a semi-professional coder conducted programming courses for 6 weeks. This course does not include the code part of the programming but focused only programming algorithm. Basically, this course includes following topics;

$1^{\text {st }}$ Week: What is Algorithm?

$2^{\text {nd }}$ Week: Flow Charts

$3^{\text {rd }}$ Week: Operators

$4^{\text {th }}$ Week: Variables

$5^{\text {th }}$ Week: Decision Structures

$6^{\text {th }}$ Week: Loop structures

These topics were taught through lots of applied examples. The students were asked to write their own algorithms for given situations and problems. The students in the control group was continued their regular information technology course which does not include the topic of algorithm but other computer science topics.

At the week following the end of the courses, both students of experimental group and control group were subjected to the same games again as post-tests and their progress was evaluated comparatively.

\section{RESULTS AND DISCUSSION}

The pre-test scores of experimental group and control group can be seen Table I and Table II respectively.
TABLE I: THE PRE-TEST SCORES OF EXPERIMENTAL GROUP

\begin{tabular}{|l|c|c|c|c|c|}
\hline Students & $\begin{array}{c}\text { Shape } \\
\text { Fold }\end{array}$ & $\begin{array}{c}\text { Sliding } \\
\text { Puzzle }\end{array}$ & $\begin{array}{c}\text { Color } \\
\text { Tangle }\end{array}$ & $\begin{array}{c}\text { Unblock } \\
\text { Me }\end{array}$ & Total \\
\hline S_01 & 3 & 0 & 6 & 3 & 12 \\
\hline S_02 & 3 & 2 & 6 & 3 & 14 \\
\hline S_03 & 3 & 0 & 7 & 3 & 13 \\
\hline S_04 & 4 & 0 & 5 & 3 & 12 \\
\hline S_05 & 3 & 0 & 3 & 2 & 8 \\
\hline S_06 & 4 & 0 & 5 & 3 & 12 \\
\hline S_07 & 5 & 0 & 6 & 3 & 14 \\
\hline S_08 & 5 & 5 & 6 & 4 & 20 \\
\hline S_09 & 4 & 0 & 6 & 2 & 12 \\
\hline S_10 & 2 & 0 & 6 & 3 & 11 \\
\hline S_11 & 4 & 0 & 4 & 2 & 10 \\
\hline S_12 & 3 & 3 & 8 & 3 & 17 \\
\hline S_13 & 3 & 0 & 4 & 3 & 10 \\
\hline S_14 & 3 & 2 & 5 & 5 & 15 \\
\hline S_15 & 3 & 0 & 4 & 2 & 9 \\
\hline S_16 & 3 & 5 & 8 & 4 & 20 \\
\hline S_17 & 4 & 0 & 6 & 6 & 16 \\
\hline S_18 & 4 & 2 & 6 & 3 & 15 \\
\hline Average & 3,5 & 1,05 & 5,61 & 3,16 & 13,33 \\
\hline
\end{tabular}

TABLE II: THE PRE-TEST SCORES OF CONTROL GROUP

\begin{tabular}{|l|c|c|c|c|c|}
\hline Students & $\begin{array}{c}\text { Shape } \\
\text { Fold }\end{array}$ & $\begin{array}{c}\text { Sliding } \\
\text { Puzzle }\end{array}$ & $\begin{array}{c}\text { Color } \\
\text { Tangle }\end{array}$ & $\begin{array}{c}\text { Unblock } \\
\text { Me }\end{array}$ & Total \\
\hline S_19 & 4 & 3 & 6 & 3 & 16 \\
\hline S_20 & 3 & 0 & 3 & 1 & 7 \\
\hline S_21 & 4 & 4 & 4 & 2 & 14 \\
\hline S_22 & 2 & 1 & 6 & 3 & 12 \\
\hline S_23 & 3 & 4 & 2 & 2 & 11 \\
\hline S_24 & 2 & 0 & 3 & 3 & 8 \\
\hline S_25 & 4 & 0 & 4 & 1 & 9 \\
\hline S_26 & 4 & 3 & 4 & 0 & 11 \\
\hline S_27 & 4 & 0 & 5 & 2 & 11 \\
\hline S_28 & 5 & 3 & 7 & 3 & 18 \\
\hline S_29 & 3 & 0 & 4 & 1 & 8 \\
\hline S_30 & 2 & 0 & 6 & 2 & 10 \\
\hline S_31 & 3 & 0 & 3 & 3 & 9 \\
\hline S_32 & 4 & 0 & 5 & 1 & 10 \\
\hline S_33 & 5 & 0 & 6 & 2 & 13 \\
\hline S_34 & 3 & 1 & 6 & 1 & 11 \\
\hline S_35 & 4 & 5 & 5 & 1 & 15 \\
\hline S_36 & 2 & 0 & 7 & 1 & 10 \\
\hline Average & 3,38 & 1,33 & 4,77 & 1,77 & 11,27 \\
\hline
\end{tabular}

It can be observed from the Table I and Table II that the total average point of the experimental group is 13,33 and the total average point of the control group is 11,27 which can be commented as their problem solving skills at the beginning of the study was very close.

Then, a computer teacher who is also a coder conducted courses for 6 weeks on algorithm. This course included lots examples which provide solutions to simple problems that can be solved through programming. At the end of these courses, both students of experimental group and control group were subjected to the same games again. The post-test scores of experimental group and control group can be seen Table III and Table IV respectively.

Table III shows that the total average point of the experimental group is 15,11 while the total average point of the control group is 12,2. The paired samples t-test analysis of the study suggest that there is a significant difference $(p<0.05)$ between the experimental group and the control 
group according to their problem solving skills in favor of the experimental group as it can be seen in Table V.

TABLE III: THE POST-TEST SCORES OF EXPERIMENTAL GROUP

\begin{tabular}{|l|c|c|c|c|c|}
\hline Students & $\begin{array}{c}\text { Shape } \\
\text { Fold }\end{array}$ & $\begin{array}{c}\text { Sliding } \\
\text { Puzzle }\end{array}$ & $\begin{array}{c}\text { Color } \\
\text { Tangle }\end{array}$ & $\begin{array}{c}\text { Unblock } \\
\text { Me }\end{array}$ & Total \\
\hline S_01 & 5 & 4 & 6 & 2 & 17 \\
\hline S_02 & 3 & 3 & 6 & 2 & 14 \\
\hline S_03 & 3 & 0 & 8 & 2 & 13 \\
\hline S_04 & 4 & 5 & 6 & 2 & 17 \\
\hline S_05 & 2 & 0 & 3 & 2 & 7 \\
\hline S_06 & 5 & 1 & 6 & 4 & 16 \\
\hline S_07 & 5 & 0 & 7 & 2 & 14 \\
\hline S_08 & 5 & 4 & 7 & 2 & 18 \\
\hline S_09 & 4 & 0 & 6 & 3 & 13 \\
\hline S_10 & 3 & 0 & 6 & 4 & 13 \\
\hline S_11 & 3 & 0 & 5 & 3 & 11 \\
\hline S_12 & 3 & 3 & 7 & 5 & 18 \\
\hline S_13 & 4 & 0 & 5 & 3 & 12 \\
\hline S_14 & 4 & 0 & 5 & 5 & 14 \\
\hline S_15 & 5 & 0 & 7 & 2 & 14 \\
\hline S_16 & 4 & 4 & 8 & 6 & 22 \\
\hline S_17 & 4 & 4 & 7 & 5 & 20 \\
\hline S_18 & 6 & 3 & 7 & 3 & 19 \\
\hline Average & 4 & 1,72 & 6,22 & 3,16 & 15,11 \\
\hline
\end{tabular}

TABLE IV: THE POST-TEST SCORES OF CONTROL GROUP

\begin{tabular}{|l|c|c|c|c|c|}
\hline \multicolumn{1}{|c}{ TABLE IV: THE POST-TEST SCORES OF CONTROL GROUP } \\
\hline Students & $\begin{array}{c}\text { Shape } \\
\text { Fold }\end{array}$ & $\begin{array}{c}\text { Sliding } \\
\text { Puzzle }\end{array}$ & $\begin{array}{c}\text { Color } \\
\text { Tangle }\end{array}$ & $\begin{array}{c}\text { Unblock } \\
\text { Me }\end{array}$ & Total \\
\hline S_19 & 4 & 0 & 5 & 3 & 12 \\
\hline S_20 & 4 & 0 & 3 & 2 & 9 \\
\hline S_22 & 5 & 0 & 6 & 4 & 15 \\
\hline S_23 & 4 & 0 & 6 & 2 & 12 \\
\hline S_24 & 4 & 3 & 5 & 2 & 13 \\
\hline S_25 & 4 & 0 & 3 & 1 & 8 \\
\hline S_26 & 2 & 1 & 6 & 2 & 16 \\
\hline S_27 & 4 & 1 & 5 & 3 & 7 \\
\hline S_28 & 5 & 2 & 6 & 6 & 13 \\
\hline S_29 & 2 & 3 & 6 & 1 & 19 \\
\hline S_30 & 4 & 0 & 7 & 4 & 15 \\
\hline S_31 & 4 & 2 & 3 & 3 & 12 \\
\hline S_32 & 4 & 0 & 5 & 0 & 9 \\
\hline S_33 & 4 & 2 & 6 & 1 & 13 \\
\hline S_34 & 4 & 0 & 7 & 2 & 13 \\
\hline S_35 & 4 & 2 & 5 & 2 & 13 \\
\hline S_36 & 2 & 0 & 6 & 2 & 10 \\
\hline Average & 3,72 & 1,11 & 5,05 & 2,38 & 12,2 \\
\hline
\end{tabular}

TABLE V: PAIRED SAMPLES T-TEST ANALYSIS

\begin{tabular}{|l|l|l|l|l|l|}
\hline & $\mathrm{t}$ & $\mathrm{df}$ & $\begin{array}{l}\text { Sig. } \\
(2 \text {-tailed) }\end{array}$ & $\begin{array}{l}\text { Mean } \\
\text { Difference }\end{array}$ & $\begin{array}{l}\text { Std. Error } \\
\text { Difference }\end{array}$ \\
\hline $\begin{array}{l}\text { Problem } \\
\text { Solving } \\
\text { Skill Tests }\end{array}$ & 2,572 & 34 &, 015 & 2,83333 & 1,10168 \\
\hline
\end{tabular}

As the results and analysis of the study suggested, the algorithm course may have a positive impact on the problem solving skills of the elementary school students.

\section{CONClusion}

Attaining knowledge and skills in computer sciences inevitably have cognitive consequences. It may be possible to detect, direct, utilize and also take advantage of these consequences. In this study the problem solving skills were focused as a cognitive consequence since it can be regarded as one of the basic skills that everyone including/especially students require in order to overcome problems they face every day. Therefore improving the potential of this skill can be considered one of the basic missions of an education system. Any medium that help to improve this skill should be studied and then implemented to the education systems. Therefore, in this study, it is aimed to investigate that if teaching algorithm at earlier ages does have any contribution to the problem solving skills of the elementary school students. The results of the study indicate that teaching algorithm has a positive effect on the problem solving skills of elementary school students. Naturally, it might be a hasty decision to reach this conclusion through this modest study with that many students and that limited time period but this study was hoped to constitute a steppingstone for longer-period and more crowded studies. The cognitive consequences of the teaching information technology courses should be studied in order to reprogram the curriculum of this course. The suggestions from this study might be that either algorithm should be integrated to the curriculum of current information technology/computer science courses in elementary or high schools or there should be a separate course titled as "Algorithm and Programming". Actually the latter one was the basic idea behind this study since Turkish Ministry of Education opened that for discussion. Consequently, the findings of this study also support the helpful consequences of learning algorithm and programming for elementary school students in order to develop their problem solving skills.

\section{A. Limitations of the Study}

This study is limited to;

a. Problem solving skills only,

b. The subject of algorithm only,

c. 36 elementary school students,

d. The school in the city of Adana in Turkey,

e. 8 weeks

\section{B. Recommendations for Future Studies}

Not only problem solving skills but also other cognitive consequences of the teaching information technology can be studied as well.

This study can be conducted again with more students for longer period of time.

This study can be conducted again in other parts of the world considering their cultural and educational differences.

\section{ACKNOWLEDGMENT}

Z. Kazanci thanks to his students; Abdullah, Gizem, Sadik, Samuel, Sezer, and Ugur for their contribution in the implementation of the study and special thanks to Akin for conducting algorithm courses and Abdullah Cemil for reserving his classroom hours for our use. Without their contribution this study could be inadequate.

\section{REFERENCES}

[1] P. Van-Roy and S. Haridi, Concepts, Techniques, and Models of Computer Programming, MIT press, 2004.

[2] R. S. RIST, Plans in Programming: Definition, Demonstration, and Development, in Empirical Studies of Programmers, Ablex Publishing, Norwood, NJ, 1986.

[3] S. Papert, Mindstorms: Children, Computers, and Powerful Ideas, Basic Books, Inc., 1980

[4] T. H. Cormen, Introduction to Algorithms, MIT press, 2009. 
[5] R. E. Neapolitan and K. Naimipour, Foundations of Algorithms, Jones \& Bartlett Learning, 2011.

[6] P. H. Dave, Design and Analysis of Algorithms, Pearson Education India, 2009.

[7] V. H. Allan and M. V. Kolesar, "Teaching computer science: A problem solving approach that works," in Proc. the Annual National Educational Computing Conference 17th, Minneapolis, Minnesota, June 11-13, 1996.

[8] R. E. Mayer, Teaching and Learning Computer Programming: Multiple Research Perspectives, Routledge, 2013.

[9] L. B. Resnick and R. Glaser, "Problem solving and intelligence," in The Nature of Intelli- gence, L.B. Resnick (ed.), Erlbaum Associ- ates, Hillsdale, NJ, 1976,

[10] G. Butterworth and B. Hopkins, "Hand-mouth coordination in the new-born baby," British Journal of Developmental Psychology, vol. 6 , pp. 303-314, 1988.

[11] M. P. Sharma and C. A. Heaney, "Evaluation of a brief intervention based on social cognitive theory to develop problem-solving skills among sixth-grade children," Health Education and Behavior, vol. 26 , pp. 465-477, 1999.

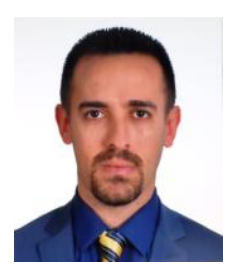

Zekeriya Kazanci was born in KahramanmarasTurkey in 1977. He got his bachelor degree in English language teaching at Çukurova University in 2001 in Adana / Turkey and then since he wanted to study interdisciplinary subjects he got his master degree in computer education and instructional technologies department of same university in 2003. Now he is working on his $\mathrm{PhD}$ dissertation in the same department. He usually concentrates his studies on the integration of educational technologies into language teaching.

He has accomplished his military service in 2006 in Turkish General Staff as a liaison officer. He worked as an English teacher from 2001 to 2005 . Since 2005 he has been working as an instructor at Çukurova University, Computer Education and Instructional Technologies Department in Adana / Turkey. One of his study fields is the utilization of computer games to teach English vocabulary. Currently he is working on mobile apps to enhance vocabulary teaching. 